\title{
A rare case of large cell neuroendocrine carcinoma
}

\author{
Diwei Lin, Amanda Jia Hui Tan, Agnelo Francis De Sousa, Rajinder Singh-Rai
}

Division of Surgery, Lyell McEwin Hospital, Elizabeth vale, South Australia, Australia

\section{Correspondence to Dr Diwei Lin,} diwei.lin1@gmail.com

Accepted 8 October 2014

\section{SUMMARY}

We present a very rare case of de novo large cell neuroendocrine carcinoma (LCNEC) of the prostate in an 84-year-old man on a background of high grade, superficially invasive transitional cell carcinoma of the bladder. Pure LCNEC of the prostate is extremely rare. Most LCNEC of the prostate are thought to originate by clonal progression under the selection pressure of therapy and refractory to long-term hormonal treatment for adenocarcinoma of the prostate. De novo LCNEC is only described in case reports and is thought to develop via direct malignant transformation. Limited data in the English literature makes it difficult to accurately predict the prognosis of LCNEC of the prostate. However, current evidence suggesting that increasing neuroendocrine differentiation in prostate adenocarcinoma is associated with a higher stage, high-grade disease and a worse prognosis.

\section{BACKGROUND}

Prostate cancer is the most common cancer in Australian men (excluding non-melanoma skin cancer), accounting for $30.2 \%$ of all new cancers in men in 2009. ${ }^{1}$ The risk of developing prostate cancer before the age of 85 in Australian men is 1 in $5 .{ }^{1}$ Furthermore, it has been estimated that, in Western countries, men have about a $10 \%$ chance of developing prostate cancer and a three to four per cent chance of dying of causes directly related to prostate cancer. ${ }^{2}$ In 2010, there were 3235 deaths from prostate cancer, accounting for $13.3 \%$ of all cancer deaths in men in Australia. ${ }^{1}$

Histopathologically, 95\% of all reported prostate cancers are adenocarcinoma. Prostatic neuroendocrine (NE) tumours are much less common and represent less than $0.5 \%$ of all diagnosed prostate carcinomas. ${ }^{3}$ The majority of prostatic NE tumours are small cell in origin with the more unusual large cell NE carcinoma (LCNEC) only being described in isolated case reports or small series of $<10$ cases from tertiary referral centres.

We report a further case of LCNEC in an elderly man with newly diagnosed prostate cancer.

\section{CASE PRESENTATION}

An 84-year-old man presented with visible painless haematuria and obstructive renal failure. This was on an extensive medical history including a partial gastrectomy for adenocarcinoma of the stomach, type II diabetes mellitus, deep vein thrombosis, pulmonary embolism and also severe ischaemic heart disease. His urological history was also significant for the following-a previous nephroureterectomy in 2008 for a grade 3 papillary transitional cell carcinoma (TCC) of the mid ureter, UICC stage pT3a; and a grade 3 TCC of the bladder diagnosed in 2007, focally invading the superficial lamina propria, UICC stage pT1, with two recurrences over the next 2 years, also staged as G3pT1. He had received adjuvant chemotherapy comprising of gemcitabine and carboplatin postnephroureterectomy and also received a 6 -week course of induction intravesical Bacillus Calmette-Guerin treatment after his first recurrence of G3pT1 bladder TCC.

Clinically he was haemodynamically stable. The abdomen was soft and non-tender on palpation. Initial blood tests showed a creatinine of $165 \mu \mathrm{mol} /$ $\mathrm{L}$ with urea of $15.2 \mathrm{mmol} / \mathrm{L}$. His white cell count remained within normal limits at $8.8 \times 10 \times 9 / \mathrm{L}$ with a haemoglobin of $101 \mathrm{~g} / \mathrm{L}$. An in-dwelling catheter was inserted and bladder irrigation started with small amounts of intravesical blood clots evacuated. At the time of his presentation he was not receiving any active treatment for his previous urological cancers as he had been lost to follow-up and as such had not seen any oncologists or urologists.

On the first day of his admission he continued to have significant ongoing haematuria with clot retention and was subsequently scheduled for an inpatient cystoscopy. Examination underanaesthesia while the patient was sedated noted a firm feeling left lobe of the prostate with suggestion of a mobile vesical mass. Cystoscopic findings noted a hard irregular area over the left hemiprostate suggestive of TCC invading into the prostate. Loop resection of the lesion and left hemi-lobe of the prostate was performed.

Microscopy showed that the prostate had been infiltrated by a high-grade urothelial carcinoma. There were also islands of large cell carcinoma noted in the prostatic parenchyma (figures 1 and 2). The tumour cells formed variable sized, solid nests with foci of microscopic necrosis in the centre

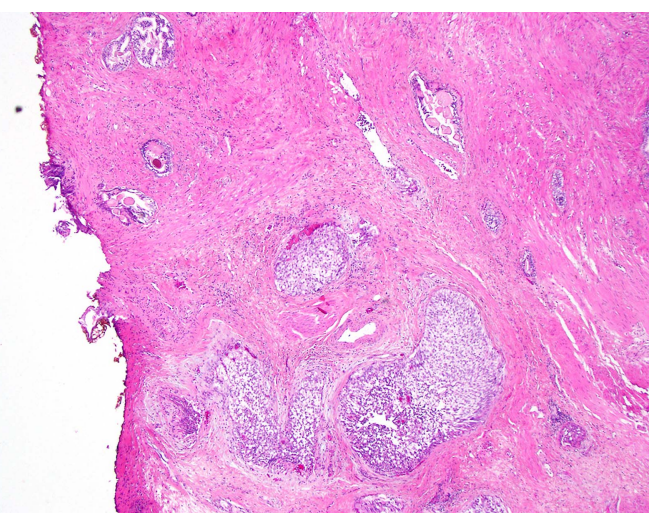

Figure 1 Scan power view showing tumour in the lower half with benign prostatic parenchyma in the upper half, $H \& E$. 


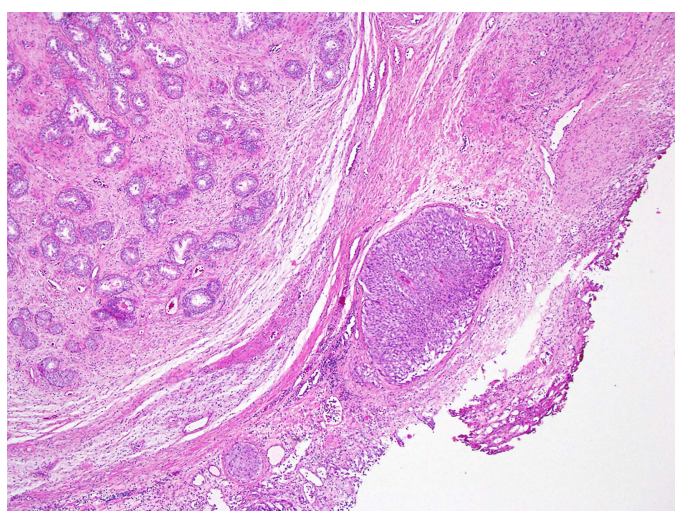

Figure 2 Scan power view showing tumour in the lower half with benign prostatic parenchyma in the upper half, H\&E.

(figure 3). The neoplastic cells were large, polygonal cells with abundant, eosinophilic to somewhat clear cytoplasm with pleomorphic nuclei with distinct nucleoli (figure 4). Lymphovascular emboli were present (figure 5). Immunohistochemistry showed that the tumour cells were accentuated with 34BE12, a high molecular weight cytokeratin (figure 6).

\section{INVESTIGATIONS}

A CT scan performed showed an irregular mass contiguous with the prostate and base of bladder, suggestive of bladder tumour invading into the prostate (figures 7-10).

\section{OUTCOME AND FOLLOW-UP}

On the basis of above findings, his bladder cancer was restaged as T4 N1 M0. He was discussed at the uro-oncology multidisciplinary team meeting and subsequently referred to radiation oncology for consideration of intensive radiotherapy. However, given his severe ischaemic heart disease, he was deemed him too frail for this and instead offered palliative radiotherapy if required. He was given palliative care support in the community and while he continued to have intermittent gross haematuria, this spontaneously resolved and the patient did not require palliative radiotherapy. He lived at home for a further 1 year before passing away in his sleep.

\section{DISCUSSION}

NE tumours account for 1-5\% of all cases of prostate cancer and scattered NE cells can be found in 10-100\% of prostate

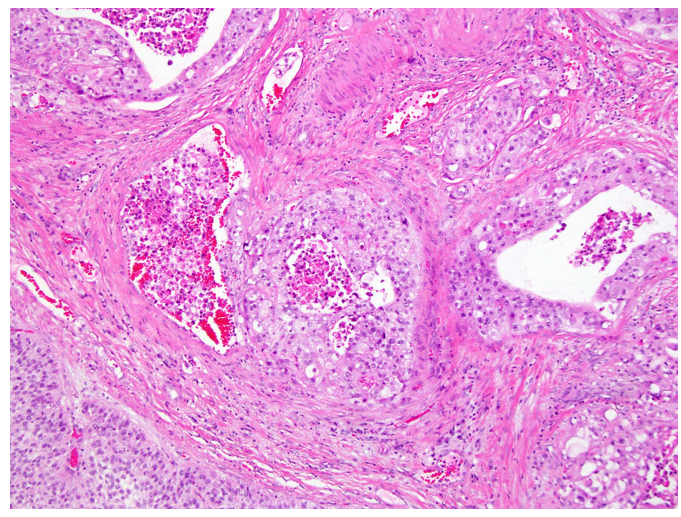

Figure 3 Low power view showing variable sized nests of tumour with foci of necrosis in the centre, H\&E.

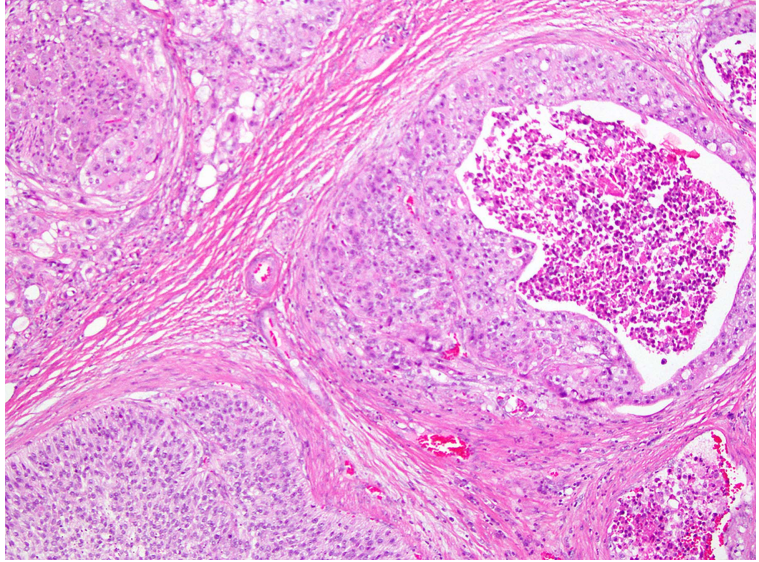

Figure 4 Low power view showing variable sized nests of polygonal tumour cells with foci of necrosis in the centre, H\&E.

adenocarcinomas. ${ }^{4}$ The majority demonstrate small cell morphology with pure LCNEC being extremely rare. ${ }^{4}$

Abrahamsson et $a l^{5}$ described a clear association between the use of hormonal therapy in the treatment of prostate cancer and the presence of increasing numbers of NE cells in prostate specimens. Increasing numbers of NE cells are thought to originate

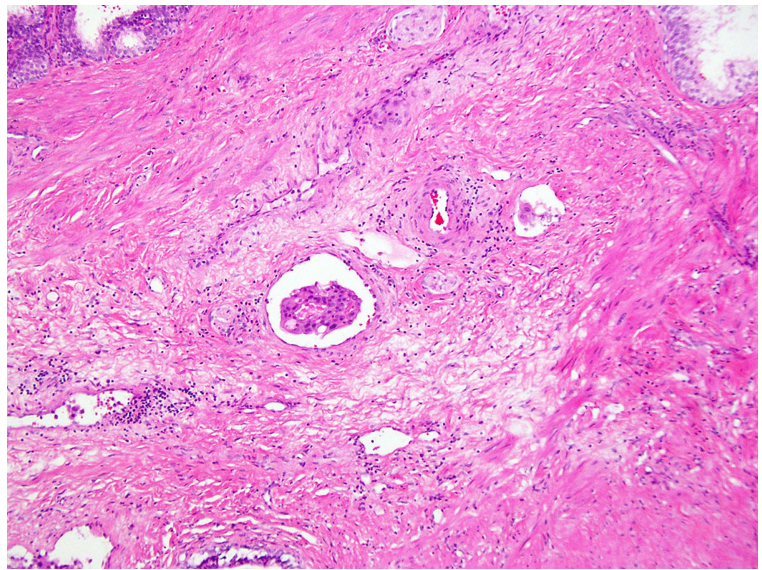

Figure 5 Low power view showing tumour emboli, the arrow points to the blood vessel, $\mathrm{H} \& \mathrm{E}$.

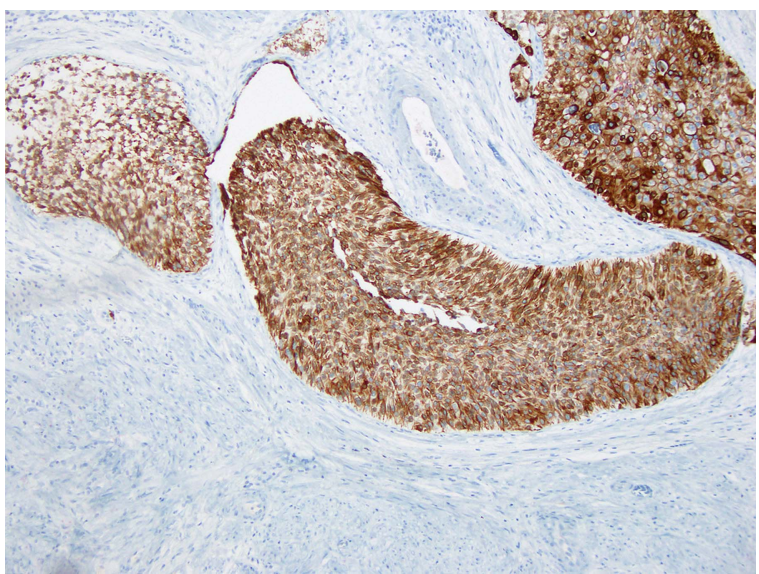

Figure 6 Low power view showing tumour cells accentuated with high molecular weight cytokeratin 34BE12. 


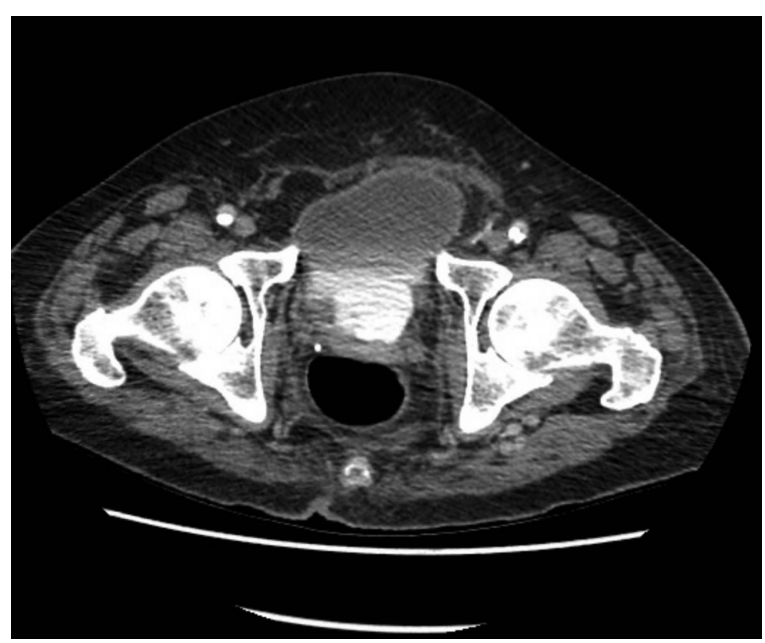

Figure $7 \mathrm{CT}$ transverse view of bladder showing an irregular mass contiguous with the prostate and base of bladder.

by clonal progression under the selection pressure of therapy ${ }^{6}$ and support for this theory is provided by animal studies in which a probasin-large $\mathrm{T}$ antigen transgenic mouse line developed prostate adenocarcinoma and NE carcinoma after being linked with SV40 T-antigen. In this study, higher grade disease developed progressively into greater NE differentiation and a high percentage of metastases.

Most reports of LCNEC of the prostate have occurred in patients refractory to long-term hormonal therapy for treatment of adenocarcinoma of the prostate. Evans et $a l^{8}$ described a series of seven patients with LCNEC of the prostate with six of the seven patients having had an initial diagnosis of adenocarcinoma of the prostate and subsequent long-term hormonal therapy. Only one of the seven patients had a de novo LCNEC, similar to the patient presented in this report. Although de novo transformation is unusual Garabedian et $a l^{9}$ has demonstrated direct transformation in a transgenic mouse model of $\mathrm{NE}$ tumours via direct malignant transformation.

Prostatic involvement by TCC in patients with bladder cancer is well documented in the literature. Shen $e t a l^{10}$ examined 214 radical cystoprostatectomy specimens and noted prostatic involvement by TCC in 69 of 214 cases (32\%). Among these 69 cases, $30(43 \%)$ patients had carcinoma in situ and the other

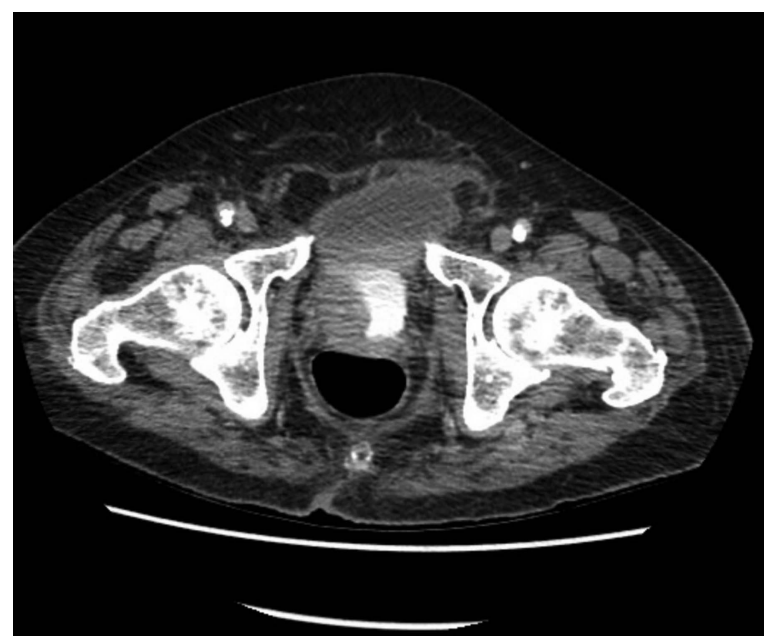

Figure 8 CT transverse view of bladder showing an irregular mass contiguous with the prostate and base of bladder.

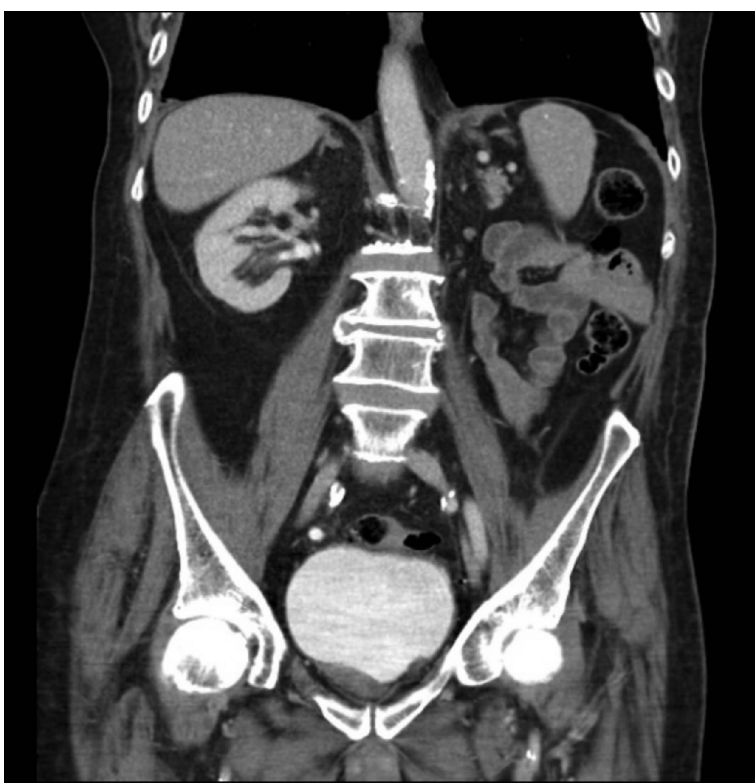

Figure 9 CT coronal view of bladder showing an irregular mass contiguous with the prostate and base of bladder.

$39(57 \%)$ were invasive TCC. However, a review of the English literature at this time provides no evidence to suggest a causative link between bladder TCC and LCNEC of the prostate.

Furthermore, while mitomycin-C has shown good antitumour activity in a phase II chemotherapy study for the treatment of metastatic prostate cancer, we have been unable to establish any potential links between the use of mitomycin $\mathrm{C}$ immunotherapy for the treatment of bladder TCC in this patient and his subsequent development of LCNEC of the prostate. ${ }^{11}$

Limited published data makes it difficult to draw conclusions on the prognosis of LCNEC of the prostate. Most evidence available is based on small case series or isolated case reports. Of the seven patients involved in a case series reported by Evans et $a l,{ }^{8}$ six patients died with wide-spread metastases to a variety of organs including bone, lung, liver, lymph nodes and brain.

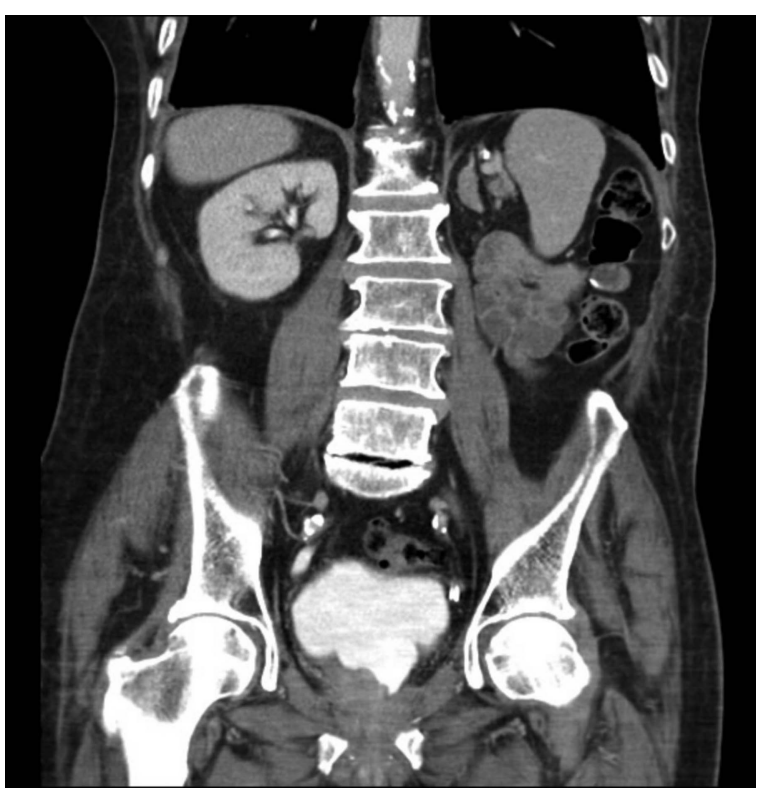

Figure $10 \mathrm{CT}$ coronal view of bladder showing an irregular mass contiguous with the prostate and base of bladder. 
All six patients received platinum-based palliative chemotherapy with a mean survival of 7 months and all had adenocarcinoma of the prostate treated with long-term hormonal therapy. It therefore appears intuitive that the appearance of the LCNEC phenotype in these patients is a manifestation of progressive androgen-resistant disease likely to result in an aggressive course and poorer outcomes. Support for this conclusion is substantiated by the current evidence suggesting that increasing NE differentiation in prostate adenocarcinoma is associated with a higher stage, high-grade disease and a worse prognosis. ${ }^{12} 13$

\section{Patient's perspective}

I was extremely grateful for the attentive care and prompt treatment I was given. Despite the poor prognosis, my care was coordinated well between the surgical and oncology teams and resulted in an early return home, which I very much appreciated.

\section{Learning points}

- Neuroendocrine (NE) tumours account for only $0.5 \%$ of all cases of prostate cancer and scattered NE cells can be found in $10-100 \%$ of prostate adenocarcinomas.

- Most large cell NE carcinoma (LCNEC) of the prostate have been described in patients refractory to long-term hormonal treatment for adenocarcinoma of the prostate.

- De novo LCNEC of the prostate is thought to develop via direct malignant transformation as shown in a transgenic mouse model.

- No evidence to suggest a causative link between bladder transitional cell carcinoma and LCNEC of the prostate.

- Increasing NE differentiation in prostate adenocarcinoma is associated with a higher stage, high-grade disease and a worse prognosis.
Contributors All authors have been closely involved in the care of this patient. They have contributed significantly to the compilation of the case history and ongoing management of this patient.

Competing interests None.

Patient consent Obtained.

Provenance and peer review Not commissioned; externally peer reviewed.

\section{REFERENCES}

1 Australian Institute of Health and Welfare \& Australasian Association of Cancer Registries 2012. Cancer in Australia: an overview. 2012. Cancer series no. 74. Cat. no. CAN 70. Canberra: AlHW.

2 Murphy G, Griffiths K, Denis L, et al., eds. Epidemiology and natural history of prostate cancer. Proceedings of the First International Consultation on Prostate Cancer; 20 June 1997. Paris.

3 di Sant'Agnese PA, Cockett AT. Neuroendocrine differentiation in prostatic malignancy. Cancer 1996;78:357-61.

4 Aprikian AG, Cordon-Cardo C, Fair WR, et al. Characterization of neuroendocrine differentiation in human benign prostate and prostatic adenocarcinoma. Cancer 1993;71:3952-65.

5 Abrahamsson PA, Falkmer S, Falt K, et al. The course of neuroendocrine differentiation in prostatic carcinomas. An immunohistochemical study testing chromogranin A as an "endocrine marker". Pathol Res Pract 1989;185:373-80.

6 Jongsma J, Oomen M, Noordzij M, et al. Different profiles of neuroendocrine cells differentiation evolve in the $\mathrm{PC}-310$ human prostate cancer model during long-term androgen deprivation. Prostate 2002;50:203-15.

7 Masumori N, Thomas TZ, Chaurand P, et al. A probasin-large T antigen transgenic mouse line develops prostate adenocarcinoma and neuroendocrine carcinoma with metastatic potential. Cancer Res 2001;61:2239-49.

8 Evans AJ, Humphrey PA, Belani J, et al. Large cell neuroendocrine carcinoma of prostate: a clinicopathologic summary of 7 cases of a rare manifestation of advanced prostate cancer. Am I Surg Pathol 2006;30:684-93.

9 Garabedian EM, Humphrey PA, Gordon JI. A transgenic mouse model of metastatic prostate cancer originating from neuroendocrine cells. Proc Natl Acad Sci USA 1998;95:15382-7.

10 Shen S, Lerner S, Muezzinoglu B, et al. Prostatic involvement by transitional cell carcinoma in patients with bladder cancer and its prognostic significance. Hum Pathol 2006;37:726-34.

11 Jones W, Fossa S, Bono A, et al. Mitomycin-C in the treatment of metastatic prostate cancer: report on an EORTC phase II study. World J Urol 1986;4:182-5.

12 Berner $A$, Nesland JM, Waehre $H$, et al. Hormone resistant prostatic adenocarcinoma. An evaluation of prognostic factors in pre- and post-treatment specimens. Br J Cancer 1993;68:380-4.

13 Weinstein MH, Partin AW, Veltri RW, et al. Neuroendocrine differentiation in prostate cancer: enhanced prediction of progression after radical prostatectomy. Hum Pathol 1996;27:683-7.

Copyright 2014 BMJ Publishing Group. All rights reserved. For permission to reuse any of this content visit http://group.bmj.com/group/rights-licensing/permissions.

BMJ Case Report Fellows may re-use this article for personal use and teaching without any further permission.

Become a Fellow of BMJ Case Reports today and you can:

- Submit as many cases as you like

- Enjoy fast sympathetic peer review and rapid publication of accepted articles

- Access all the published articles

- Re-use any of the published material for personal use and teaching without further permission

For information on Institutional Fellowships contact consortiasales@bmjgroup.com

Visit casereports.bmj.com for more articles like this and to become a Fellow 